\title{
The role of cultural values in consumers' evaluation of online review helpfulness: a big data approach
}

Article

Accepted Version

Filieri, R. and Mariani, M. (2021) The role of cultural values in consumers' evaluation of online review helpfulness: a big data approach. International Marketing Review. ISSN 0265-1335 doi: https://doi.org/10.1108/IMR-07-2020-0172 Available at https://centaur.reading.ac.uk/98443/

It is advisable to refer to the publisher's version if you intend to cite from the work. See Guidance on citing.

To link to this article DOI: http://dx.doi.org/10.1108/IMR-07-2020-0172

Publisher: Emerald

All outputs in CentAUR are protected by Intellectual Property Rights law, including copyright law. Copyright and IPR is retained by the creators or other copyright holders. Terms and conditions for use of this material are defined in the End User Agreement.

www.reading.ac.uk/centaur 
Central Archive at the University of Reading

Reading's research outputs online 
The role of cultural values in consumers' evaluation of online review helpfulness: a big data approach

\section{Abstract}

Purpose - Online consumer reviews are increasingly used by third-party e-commerce organizations to shed light on the positive and negative sides of the brands they sell. However, the large number of consumer reviews requires these organizations to shortlist the most helpful ones to cope with information overload. A growing number of scholars have been investigating the determinants of review helpfulness; however, little is known about the influence of cultural factors in consumer's evaluation of review helpfulness.

Design/methodology/approach - This study has adopted Hofstede's cultural values framework to assess the influence of cultural factors on review helpfulness. We used a sample of 570,669 reviews of 851 hotels published by reviewers from 81 countries on Booking.com.

Findings - Findings reveal that reviewers from cultural contexts that score high on power distance, individualism, masculinity, uncertainty avoidance, and indulgence are more likely to write helpful reviews.

Originality - This is one of the first cross-cultural studies in marketing using a big data approach in examining how users of reviews from different countries evaluate the helpfulness of online reviews.

Keywords: online consumer reviews; review helpfulness; cultural factors; Hofstede cultural dimensions framework; big data; Booking.com.

\section{Introduction}


Online consumer reviews (OCRs), a digital form of word-of-mouth, have become an irreplaceable information source in consumer decision-making. More than half of U.S. adults regularly read online consumer reviews before making a purchase (Pew Research Center, 2016), and 81 percent of 18-34 year-olds seek out OCRs before purchasing a product or service (Mintel, 2015).

Scholars have demonstrated that OCRs are particularly important in e-commerce contexts as they help consumers to learn and familiarise themselves with products and services before purchasing them (Filieri, 2015); they impact companies' sales (e.g., Liu, 2006; Zhu and Zhang, 2010; Floyd et al., 2014); financial performance (e.g., Raguseo and Vitari, 2017); product considerations and choice (e.g., Senecal and Nantel, 2004); and consumer's alternatives evaluation and purchase decisions (e.g., Park et al., 2007; Christodoulides, Michaelidou, and Argyriou, 2012; Filieri et al., 2018).

The wide adoption of social media and mobile technologies has grown to the point that consumers find it difficult to orientate and to determine which information is the most helpful for them (Park and Lee, 2008). The helpfulness, or diagnosticity, of an online customer review, indicates its capacity to enable other consumers to better understand the level of quality and performance of a product or service (Jiang and Benbasat, 2007; Mudambi and Schuff, 2010; Filieri, 2015). The degree of the helpfulness of consumer reviews is particularly important for third-party e-commerce organizations since helpful reviews are deemed to increase sales (Ghose and Ipeirotis, 2011). Hence, organizations are enabling consumers to vote on how helpful a consumer review is to signal other consumers which reviews are most useful for assessing products' performance (Filieri, 2015). While several studies have investigated the antecedents of review helpfulness (e.g., Ghose and Ipeirotis, 2010; Mudambi and Schuff, 2010; Pan and Zhang, 2011; Racherla and Friske, 2012; Korfiatis, García-Bariocanal, and Sánchez-Alonso, 2012; Yin, Bond, and Zhang, 2014; 
Filieri, 2015; Huang et al., 2015; Chua and Banerjee, 2016; Liu and Park, 2015; Park and Nicolau, 2015; Kwok and Xie, 2016; Fang et al., 2016; Singh et al., 2017; Filieri, Raguseo, and Vitari, 2018, 2019, 2020; Sun, Han, and Feng, 2019; Filieri, Galati, and Raguseo, 2021), cultural factors have been rarely considered in studies on online review helpfulness (ORH) (Park and Lee, 2009; Gao et al., 2018; Stamolampros et al., 2019).

In service research, scholars have emphasised the importance of cultural factors in customers' expectations (Donthu and Yoo, 1998; Laroche, Kalamas, and Cleveland, 2005), product choice (Money and Crotts, 2003), evaluation (Mattila, 2000; Au, Law, Buhalis, 2010; Ayeh, $\mathrm{Au}$, and Law, 2016), and satisfaction (Laroche et al., 2005; Ladhari et al., 2011). Moreover, research on consumer behaviour and international marketing has found that consumers in the emerging markets have different characteristics, values, attitudes, and behaviors compared to those of consumers in developed markets due to cultural and socio-economic differences (e.g., Michaelidou et al., 2015; Morgeson III et al., 2015). Culture appears to be particularly important in eWOM contexts; scholars found cultural differences explain product evaluations (Christodoulides et al., 2012), online rating submission (i.e., extreme and moderate ratings) as well as movies sales (i.e., review variance and average rating) in Asian (i.e., China) and Western countries (i.e., USA) (Chiu et al., 2019; Stamolampros et al., 2019; Mariani et al., 2020). Moreover, consumers from different cultures have different thinking styles (Park and Jeon, 2018), information-seeking behavior (Fong and Burton, 2008), and they search for different types of information (de Mooij, 2004), potentially affecting the way they process and evaluate information and its helpfulness (Filieri et al., 2018).

Although scholars have recommended further analyses of the role of cultural factors in the evaluation of review helpfulness (King, Racherla, and Bush, 2014; Gao et al., 2018; Filieri et al., 2018), at present, the literature lacks studies that investigate this topic. To fill this gap and advance the literature, this study a) adopt all the cultural dimensions of Hofstede's 
framework to $b$ ) examine how consumers from different cultures $c$ ) evaluate review helpfulness $d$ ) using a big data approach.

In this study, we have adopted all the dimensions of Hofstede's cultural dimensions framework (2001), which is often used by marketers in international contexts in the service sector (Liu, Furrer, and Sudharshan, 2001). Hofstede's cultural dimensions framework (2001) is deployed to understand whether the cultural dimensions of this framework (i.e., high versus low uncertainty avoidance, individualism versus collectivism, short-term versus long-term orientation, low versus high power distance, low versus high indulgence), affect consumer evaluation of review helpfulness.

To answer our research question, we have used a large dataset of 570,669 consumer reviews posted on Booking.com by consumers of 81 countries of 851 hotels in Rome. The Big data approach adopted in this paper is believed to improve the accuracy of the predictions relying on extensive consumer data, thus overcoming the limitations of small sample sizes and sampling bias (Yang et al., 2015; Li et al., 2018; Mariani et al., 2018). We choose to focus on the hotel industry as hotels receive travellers from different countries (Gao et al., 2018), and therefore, they have to pay greater attention to the culture of their customers. In the following sections, we present the theoretical framework, review the extant literature on ORH and provide the arguments according to which we describe how different cultural dimensions may affect ORH.

\section{Literature Review}

\subsection{The Hofstede's cultural dimensions framework}

Consumer behaviour literature has shown that cultural differences play a role in determining how consumers form their expectations about a product or service and later perceive and evaluate them (De Mooij and Hofstede, 2002). More specifically, the culture of origin at the 
national and local level has been found to generate differentiated attitudes, behaviours, and ultimately different levels of satisfaction with products (Aksoy et al., 2013; Frank et al., 2013; Khan et al., 2007; Liu and McClure, 2001) and with service encounters (Sharma, Wu, and Su, 2016; Tam, Sharma, and Kim, 2009; Voss et al., 2004). Interestingly consistent results have been found in online settings where culture seems to affect electronic satisfaction (Jin, Park, and Kim, 2008; Duque and Lado, 2010; Kim and Kim, 2010), adoption of ecommerce (Yoon, 2000), and rating behavior (Koh, Hu, and Clemons, 2010).

Many cross-cultural studies have deployed Hofstede's theory of cultural dimensions (Hofstede, 2001), which was originally developed as the by-product of a monumental survey the author conducted to capture employees' values working in the sales subsidiaries of the multinational company IBM over the period 1967-1973. Based on that survey, Hofstede developed a framework inductively to characterise and explain the differences found in work attitudes and values within a formal organizational structure that was the same everywhere. Hofstede found that cultural differences across countries could be explained by looking at four dimensions: a) power distance, i.e., the extent to which individual actors accept that power is distributed inequitably; $b$ ) uncertainty avoidance, i.e., individuals' tolerance for ambiguity in terms of tolerating unexpected or unknown events; c) individualism, i.e., the degree to which people in a society behave in an atomistic way or are integrated into groups; d) masculinity, i.e., the degree to which heroism, achievement assertiveness, and material rewards are appreciated in a society (Hofstede, 1976; 1980).

After a study conducted in Asia, Geert Hofstede added two new dimensions: e) long-term orientation, i.e., the degree to which individuals make sense of and decide for future actions/challenges; $f$ ) indulgence, i.e., the tendency of a society to allow gratification of basic human desires related to amusement and enjoyment (Hofstede, 2001). 
Overall, Hofstede's framework represents a dominant paradigm deployed by scholars and practitioners dealing with cross-national studies in social science and consumer behaviour studies (e.g., De Mooij and Hofstede, 2002, 2011; Soares et al., 2007).

Consumer's culture and country of origin $(\mathrm{COO})$ play a crucial role in the consumption of tourism and hospitality services and choosing tourism destinations (e.g., Agyeiwaah et al., 2016; Mattila, 1999, 2000; Mattila and Choi, 2006; Wong and Law, 2003). Moreover, various cross-cultural studies in Western (UK, USA) and Asian countries (China) have shown that culture affect product evaluations, online ratings submission, and product choice in the eWOM context (Christodoulides et al., 2012; Chiu et al., 2019; Stamolampros et al., 2019). Hofestede's framework (2001) can help understand how cultural dimensions affect the assessment of eWOM (Stamolampros et al., 2019). However, no study has adopted Hofstede's framework to study ORH. In this study, we expect that national culture orientations may affect consumers' processing of information from online reviews, and more specifically, ORH.

\subsection{Online review helpfulness}

eWOM refers to 'any positive or negative statement made by potential, actual or former consumers about a product or company, which is made available to a multitude of people and institutions via the Internet' (Hennig-Thurau et al., 2004, p. 39). OCRs, a specific type of eWOM, can be defined as any positive, negative, or neutral feedback on a product, service, brand, or person supposedly made by a former purchaser and that is shared online on thirdparty platforms (e.g., Booking.com), organisations' websites (e.g., TUI.com), social media platforms (e.g., Facebook), or search engines (e.g., Google reviews).

The literature on the determinants of ORH for services is rapidly developing. For instance, Racherla and Friske (2012) used 3,000 reviews of products (furniture stores) and services 
(restaurants and beauty spas) from Yelp and found that reviewer reputation contributes to the perception of usefulness, while reviewer expertise was negatively correlated with review usefulness. Negative reviews are perceived to be more useful than either extremely positive or moderate reviews. Liu and Park (2015) adopt Yelp reviews about London and New York's restaurants and reveal that perceived enjoyment, the number of friends, Elite awards, and fans (connoting the reviewer's reputation), the star rating, the squared star rating, and word count significantly predicted helpful votes (Liu and Park, 2015). Using the same dataset, Park and Nicolau (2015) found that extreme ratings were voted as more helpful and enjoyable than moderate ratings, giving rise to a U-shaped line. The authors reveal that the most negative reviews (star rating of 1) on TripAdvisor are the most useful, and the most positive review (5star rating) had a similar impact to the second-to-last most negative review (star rating of 2). The reviewer's 'real' photo (identity disclosure) and his/her expertise (number of reviews written by the reviewer) and word count affected usefulness and enjoyment while reviewers' 'real' name did not. Fang et al. (2016) used online consumer reviews of attractions within a tourism destination (i.e., New Orleans) from TripAdvisor and found that some reviewer characteristics, namely reviewers writing more reviews stressing positive sides (i.e., mean rating higher than rating mode), and some review characteristics, such as review readability and extremity, predicted review helpfulness. Kwok and Xie (2016) use Texas' hotel reviews from Tripadvisor to explore the impact of rating, review length, manager's response, and reviewer experience on the helpfulness of consumer reviews. Hong et al. (2017) conducted a meta-analysis of the literature on review helpfulness. They found that review depth, review age, reviewer information disclosure, and reviewer expertise have positive influences on review helpfulness, while review readability and review rating did not have a significant influence on review helpfulness. Fong, Lei, and Law (2017) used 500 reviews of a hotel on TripAdvisor. They found that dual- (vs. single-) valence reviews appear more frequently in 
extremely negative than extremely positive ratings, but less frequently in moderately negative than moderately positive ratings. Men posted more dual-valence reviews than women when the rating was extremely negative. Filieri, Raguseo, and Vitari (2018) analyse the factors that moderate the influence of extreme rating reviews (i.e., 1 and 5-strar ratings) using a French hotels review sample from TripAdvisor.com (i.e., 11,358 reviews of 90 French hotels) reveal that hotel size matters in the analysis of extreme ratings as extreme ratings are more helpful for large than for small hotels. They also found that extreme reviews are more helpful when the review is long (i.e., >100 words) and the reviewers post a photo of the establishment. In another study, Filieri, Raguseo, and Vitari $(2019,2020)$ investigate the moderators of the influence of one star rating reviews (i.e., negative ratings) on review helpfulness, investigating various factors, including reviewer factors (i.e., identity disclosure and expertise); review factors such as review length, review readability, rating score, and volume; third-party product quality signals (i.e., certificate of excellence); and traditional product quality signals (i.e., hotel high versus low category, chain versus no chain).

To summarize, the most frequently analyzed determinants so far are: the review characteristics, in terms of content quality, length, complexity, readability, rating, and extreme ratings (Liu and Park, 2015; Park and Nicolau, 2015; Fang et al., 2016; Kwok and Xie, 2016; Filieri et al., 2018, 2019), the reviewer background and characteristics, such as the reviewer's expertise, reputation, and identity disclosure (Liu and Park, 2015; Fang et al., 2016; Park and Nicolau, 2015; Filieri et al., 2019), the reviewer's photo of the product/service (Filieri et al., 2018), the product characteristics (i.e., hotel size) (Filieri et al., 2018), and attributes (Filieri, Galati, and Raguseo, 2021), and the manager response (Kwok and Xie, 2016).

In service research studies, the relationships between cross-cultural differences and consumer behaviour, service evaluation, and satisfaction have been studied over time (Hsieh and 
Chang, 2005; Manzur and Jogaratnam, 2006; Mattila, 1999; Ayeh et al., 2016) besides the research stream on cross-cultural management in hospitality (e.g., Pizam, 1993; for a review Chen et al., 2012). To the best of our knowledge, only a few studies have adopted Hofstede's framework so far to study eWOM (Christodoulides et al., 2012; Gao et al., 2018; Stamolampros et al., 2019). Park and Lee (2009) measure internet shopping experience and consumer susceptibility across Korean and American consumers on perceived review usefulness. Christodoulides et al. (2012) studied the impact of positively and negatively valenced e-WOM - i.e., eWOM-with positive and negative ratings - of search and experience products on UK and Chinese consumers' purchase intentions as well as their presentation order. Gao et al. (2018) analyse the relationship between the reviewer's power distance (PD) and online hotel ratings and find that PD exerts a negative influence on online ratings, thus mirroring what happens in offline settings where consumers from high power distance societies tend to perceive the quality of the service as poor and give low evaluation scores to service providers (Mattila, 2000). The negative effect detected is positively moderated if the hotel belongs to a chain or if the reviewer is experienced (Gao et al., 2018). Mariani et al. (2018) analyze the impact of countries of origins on online consumer review ratings in the context of hospitality. Park and Jeon (2018) analyse the impact of review ratings (positive versus negative) presentation order on attitude change across Western (US) and Asian countries (South Korea). Stamolampros et al. (2019) use online reviews from Tripadvisor and study the determinants of rating behaviour of flights and the key topics discussed in their dataset.

As it emerges from this review of the literature, there is a dearth of cross-cultural research on cultural factors' influence on ORH (Filieri et al., 2018), as all of the studies conducted in online settings have not used all the dimensions of Hofstede's value framework and have focused merely on online ratings (e.g., Stamolampros et al., 2019). Accordingly, no study so 
far has adopted Hofstede's framework to measure the influence of cultural factors on ORH or measured the influence of culture in consumers' assessment of ORH using big data (Filieri et al., 2018; Mariani and Borghi, 2020). Scholars suggest that thinking styles of Eastern and Western consumers are different (Nisbett et al., 2001; Park and Jeon, 2018; Mariani et al., 2020) and they evaluate information sources differently (Money and Crotts, 2003; Laroche et $a l ., 2005)$; hence, it is plausible to expect that consumers from different cultures and countries seek, process, and evaluate information from online reviews differently (Filieri et al., 2018).

This study aims to fill these gaps and adopts Hofstede's cultural framework (2001) to investigate whether cultural variables affect consumer behavior in assessing ORH. We adopt Hofstede's cultural framework (Hofstede, 2001), and we evaluate the predictive power of the six dimensions of this model, namely power distance (PD), individualism (IDV), masculinity (MAS), uncertainty avoidance (UA), long-term orientation (LTO) and indulgence (IND).

\section{Hypotheses development}

\subsection{Power distance (PD)}

Power distance is defined as the extent to which members of a society accept and expect that power is distributed inequitably (Hofstede, 1980). Studies conducted in offline settings in the services sector have pointed out that given the low status of employees, customers from high power distance cultures expect services to be delivered with the highest quality level (Ladhari et al., 2011; Mattila, 2000). For instance, hotel guests from Western cultures (lower power distance) have been found to give higher evaluations than hotel guests from Asian cultures (higher power distance) (Mattila, 2000; Ladhari et al., 2011). In eWOM settings, the findings seem to be highly consistent in that the reviewer's power distance is negatively related to 
online ratings, namely the reviewers from countries with higher power distance tend to provide lower online hotel ratings (Gao et al., 2018; Mariani, Di Fatta, and Di Felice, 2019). High power-distance customers have higher expectations and are more demanding than lowpower distance cultures, which implies that their evaluation will be more scrupulous and critical. Consumers are interested and value more negative and two-sided online reviews because they perceive them as more trustworthy and diagnostic (e.g., Filieri et al., 2018, 2019).

Furthermore, since the majority of consumer reviews online are predominantly positive (Park and Nicolau, 2015), negative information is more attention-catching (Herr, Kardes, and Kim, 1991), and online negative reviews are perceived as more informative (Filieri et al., 2019).

Hence, strict and rigorous evaluations are more needed and surprising, increasing interest and information elaboration. Based on these arguments, we expect that the reviews of consumers from high-distance countries will be more likely to be voted as helpful than the reviews from low-distance countries' customers. Drawing upon these findings, we hypothesize:

H1: The higher the power distance (PD), the more positive ORH.

\subsection{Individualism (IDV)}

Individualism is defined as the degree to which people in a society behave in an atomistic way or are integrated into groups (Hofstede, 1976; 1980). Individuals from collectivist societies have a tendency to place emphasis on harmony in managing all interpersonal relations (Brewer and Chen, 2007). Accordingly, collectivist consumers' pressure to conform to the group norms (Filieri et al., 2017) to keep consensus (Laroche, Kalamas, and Cleveland, 2005) would seemingly "urge" reviewers, in this case, to not deviate too much from the group, namely from the previous reviewers' comments. Previous studies proved that individuals from collectivist countries tend to conform to the views, opinions, behaviour, of 
other people (Cialdini et al., 1999; Yaveroglu and Donthu, 2002). Thus, we expect that they will be more inclined to write reviews that somehow conform to the opinion expressed by the majority of previous reviewers, producing redundant information.

On the contrary, consumers from individualistic cultures tend to express their own personal opinions and emotions in writing reviews: these opinions might be inconsistent with what other people have stated in previous reviews. Scholars have revealed that review score inconsistency significantly impacts product sales of a high involvement product like a music instrument (Eslami and Ghasemaghaei, 2018). Users from individualistic groups are also keener to express their feelings and emotions in writing reviews compared to collectivist countries (Butler, Lee, and Gross, 2007), which is important in assessing the emotional dimension of customer experience (Barsky and Nash, 2002). Moreover, reviewers from individualistic countries could be more used to articulate their own experience in writing reviews and tend not to conform to the opinions of others. Furthermore, consumers who score high on the individualist scale often show more consideration for the welfare of strangers than consumers from collectivist countries (Brewer and Chen, 2007). Indeed, Hennig Thurau et al. (2003) found that concern for others was a motive behind eWOM in Germany. Drawing on these arguments, we expect that reviewers from individualist societies will write more helpful reviews than the reviewers from collectivist cultures. Thus, we expect:

H2: The higher individualism (IDV), the higher ORH.

\subsection{Masculinity (MAS)}

Masculinity is defined as the degree to which heroism, achievement assertiveness, and material rewards are appreciated in a society (Hofstede, 1980). By contrast, femininity is related to a preference for cooperation and a caring attitude for the weak. Masculine cultures emphasize work, competition, and material accomplishments, whereas feminine societies put 
caring for others and quality of life at the forefront. When considering online consumers, we would expect individuals from highly masculine cultures to be less prone to cooperate and be less helpful to other consumers. We expect that people who value masculinity are more assertive and are more likely to voice their pleasure or displeasure about new products to those with weak ties (Lam, Lee, and Mizerski, 2009). This attitude in masculine societies will lead reviewers from this culture to express their opinions in a more aggressive way, and intense emotions like angriness may prevail in reviews written by reviewers from masculine society. Angriness negatively affects review helpfulness (Yin, Bond, and Zhang, 2014; Filieri, 2016; Cracium and Moore, 2019). Thus, in masculine societies, reviewers may tend to be more assertive, more likely to express angry feelings, and therefore less helpful.

Consequently, we hypothesize that:

H3: The higher the masculinity (MAS), the lower ORH.

\subsection{Uncertainty avoidance (UA)}

Uncertainty avoidance is defined as individuals' tolerance for ambiguity in terms of tolerating unexpected, new, surprising, or unknown events (Hofstede, 1976; 1980). By definition, services are riskier than goods as they are intangible and they are consumed at the same time they are purchased, so they are difficult to evaluate before being experienced (Parasuraman, Zeithaml, and Berry, 1985). Fong and Burton (2008) reveal that the China-based (= high level of UA) discussion boards engaged in higher information-seeking levels than their American counterparts. Hence, consumers from cultures that tend to avoid uncertainty will be more cautious when it comes to making purchase decisions, particularly in the context of risky product decisions like services (Murray and Schlacter, 1990).

Based on this literature, we can speculate that reviewers from high UA countries will be particularly careful in the writing of their reviews. Consumers who score high in uncertainty 
avoidance would provide more unambiguous and clear-cut evaluations to help others as they understand the importance of assessing the level of risk embedded in a purchase before the decision. As consumers from countries with high UA want to minimise the risk for other consumers, we expect they will be motivated to provide more accurate and detailed reviews, which are perceived as highly helpful (e.g., Filieri, 2015). Reviewers from countries with low UA levels instead are willing to accept a higher degree of ambiguity and risk, and therefore they will care less about providing thorough descriptions and details that would instead reduce the level of risk embedded in a purchase. Therefore, we conjecture that:

H4: The higher uncertainty avoidance (UA), the higher ORH.

\subsection{Long-term orientation (LTO)}

Long-term orientation (LTO) is defined as the degree to which individuals make sense of and decide for future actions/challenges (Hofstede, 2001). Bearden et al. (2006, p. 457) defined LTO as "the cultural value of viewing time holistically, valuing both the past and the future rather than deeming actions important only for their effects in the here and now or the short term." Consequently, individuals from cultures with high LTO would take more time to judge a service and consider the potential spillover effects for other consumers, which might bring to an improvement of the service. A high score in LTO would suggest that consumers value working hard and persevering for future benefits (Hassan, Shiu, and Walsh, 2011). Furthermore, LTO customers think based on long-term plans; hence, their reviewing behaviour may consider a future visit to the same service provider.

These arguments suggest that reviewers from countries that score high on LTO will be more constructive, helpful, and precise while reviewing their experience because they value the service provider's hard work and willingness to improve the offer in the future. These reviews would be generally more balanced and allow service providers to reply and 
potentially rectify or recover from a service failure, which would improve the helpfulness of a review (Kwok and Xie, 2016). Therefore, reviews from LTO customers might be voted as more helpful. Conversely, reviewers from countries that score high on short-term orientation will probably write more concise and short accounts of their experience because they would not think long-term, i.e., about the consequences of their reviewing behaviour. Reviewers from countries with short-term orientation will tend to focus on their one-off experience rather than establishing a long-term relationship with the service provider or the future customers of the same accommodation. Thus, the information provided in their reviews may lack depth and therefore be perceived as not diagnostic (Filieri, 2015). Hence, we hypothesize that:

H5: The higher long-term orientation (LTO), the more positive ORH.

\subsection{Indulgence (IND)}

Indulgence is defined as the tendency of a society to allow gratification of basic human desires related to amusement and enjoyment (Hofstede, 2001). Reviewers from countries who score high in indulgence feel freer and less inhibited in expressing their ideas and views because they tend to view everyone as equal (Lam, Lee, and Mizerski, 2009); hence, they do not feel restrained by societal norms. This means that they will be more open about expressing their experience and opinions in consumer reviews, either be extremely good or bad. Furthermore, leisure activities and time are considered particularly important to consumers who score high on indulgence on the indulgence-restraint continuum (Hofstede et $a l ., 2010)$. Conversely, restraint is also thought to be associated with lower engagement and involvement in leisure, fun, and pleasure-related activities (Hofstede et al., 2010). Hence, since indulgent consumers are more involved in leisure activities, and involvement is an antecedent of eWOM (Alhidari, Iyer, and Paswan, 2015), it is expected that they will spend 
more time and make a higher effort reviewing them (Petty, Cacioppo, and Schumann, 1983). Consequently, it is expected that they will also provide lengthier and more detailed accounts of their experience, which is generally associated with review helpfulness (Pan and Zhang, 2011), and extreme rating helpfulness (Filieri et al., 2019, 2020), and perceived information diagnosticity in eWOM (Filieri, 2015). Based on the above arguments, we hypothesize:

H6: The higher indulgence (IND), the more positive ORH.

Additional factors identified in the literature have been found to affect $\mathrm{ORH}$, such as ratings, review length, reviewer's identity disclosure, reviewer's gender, hotel star rating, type of hotel (chain and non-chain), and more. As such, the theoretical framework put forward is represented below:

Figure 1 Theoretical framework and hypotheses 


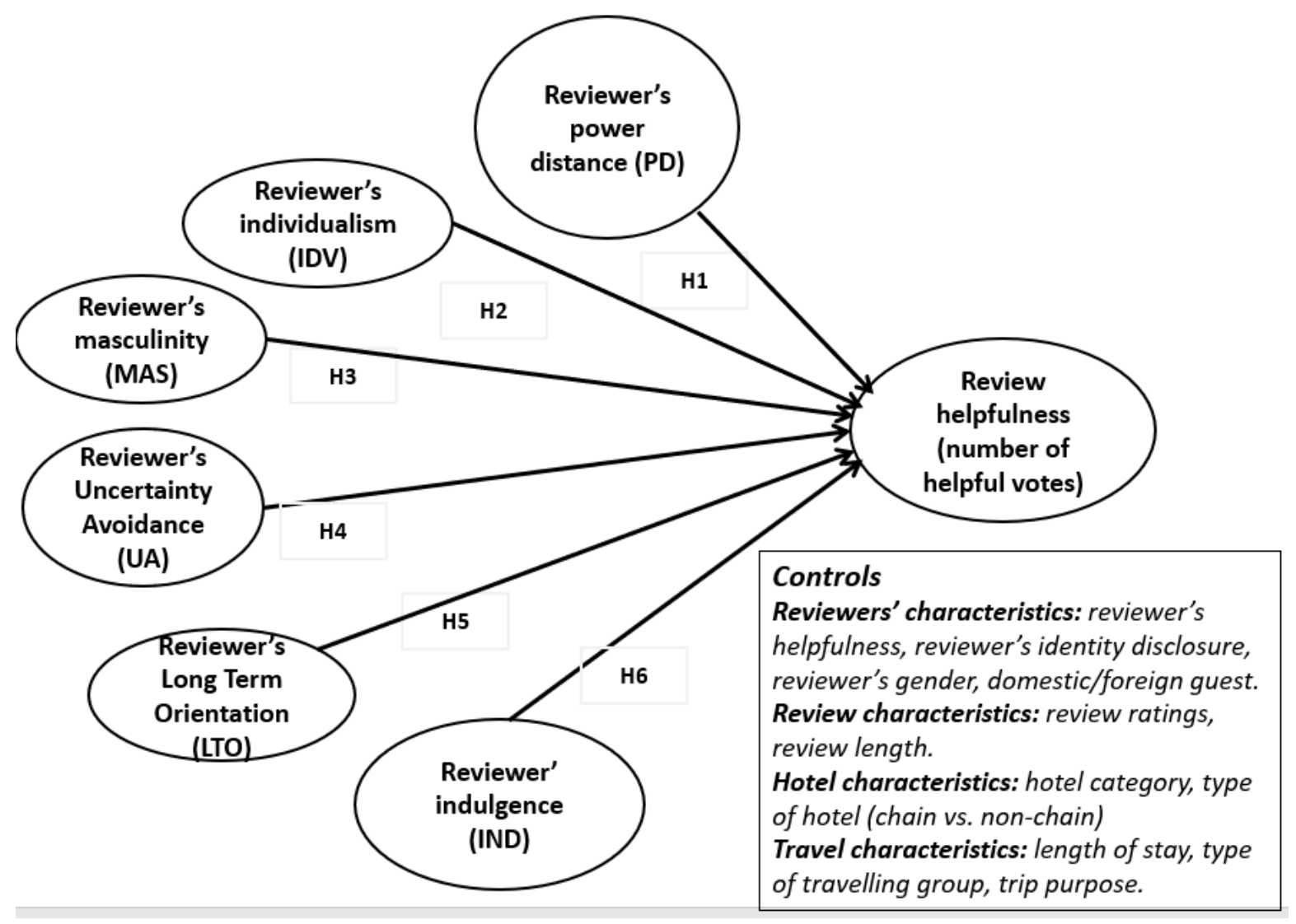

\section{Methodology}

\subsection{Context and Data collection}

This study focuses on the travel \& tourism industries, one of the largest sectors worldwide, generating $10.3 \%$ of global GDP (WTTC, 2019). In 2019, the travel \& tourism sector experienced $3.5 \%$ growth, outpacing the global economic growth of $2.5 \%$ for the ninth consecutive year (WTTC, 2019). Beyond this economic relevance, a theoretical gap exists, and it relates to the analysis of multifaceted services (i.e., hotels) and the risky consumer decision-making to book them. Data for this study (i.e., online travel reviews) were collected from Booking.com, which is currently the Online Travel Agency (OTA), hosting the highest share of certified online reviews worldwide (Mariani and Borghi, 2018). We focused on the Italian destination of Rome as it is one of the most visited city destinations in Europe, ranking fourth in Europe, based on the Euromonitor Top 100 City Destinations 2018 (Geerts, 2018), and because it is significantly under-researched in eWOM studies. The online reviews of the 
hotels in Rome were retrieved and scraped from February 2015 to February 2017 through a Python-based crawler. A number of different items were scraped, including both review level data and reviewer level data. Among the former ones, we collected the overall ratings, the timestamp, the text of the reviews, the text of the positive and negative comments (as Booking.com distinguishes these two parts), and the travel purpose.

Among the latter ones, we collected the reviewer's name, age, country of origin/residence, number of useful reviews already written, the length of stay (i.e., the number of nights spent in the hotel), the type of travelling group (solo, couple, etc.). Other data related to the hospitality firm were collected, such as name and class.

The advantage of using Booking.com data is that unlike other OTAs such as Expedia or online travel review websites such as Tripadvisor, the countries of origin of the travellers are presented consistently. The original sample included 587,816 reviews written by reviewers from 81 countries on 851 different hotels.

Moreover, we obtained the measure of the cultural dimensions (power distance, individualism, masculinity, uncertainty avoidance, long-term orientation, and indulgence) based on data from the "Hofstede Center" (https://www.hofstedeinsights.com/product/compare-countries/). As both datasets include country names, we matched the two datasets to generate a final dataset. In our original sample, including 587,816 reviews, there were missing values for both LTO and IND as some countries have not been given any value by Hofstede for those two dimensions. As such, we retained only those reviews written by reviewers from countries for which we had complete data for all the six cultural dimensions. The final sample, therefore, includes 570,669 reviews written by reviewers from 80 countries. Thus, the sample deployed is not the only representative of the tourists visiting Rome but also includes significant cultural diversity. 


\subsection{Data operationalization}

Our dependent variable is the logarithmic transformation of the number of helpful votes (augmented by 1 to avoid trivial results when calculating the logarithm of 1) obtained by each review. The independent variables include the Hofstede's cultural dimensions, namely power distance (PD), individualism (IDV), masculinity (MAS), uncertainty avoidance (UA), longterm orientation (LTO), and indulgence (IND). They were operationalized using the Hofstede indices (https://geerthofstede.com/research-and-vsm/dimension-data-matrix/). Besides, we embedded in the model specification control variables including rating, review length (RevLength), helpfulness of the reviewer (Helpful_Reviewer), the domestic or international nature of the tourist (Domestic_Tourist), the identity disclosure on the platforms (No_Id_Disclosure), the gender (Gender_Female), the length of stay (LoS), the type of travelling group (Solo_Traveller), the trip purpose (Leisure). Controls at the firm level were added, including hotel class (Hotel Star Rating) and belonging to a chain (Chain) (Filieri et al., 2018).

The description of the variables and the descriptive statistics for the relevant variables are summarised in Table 1 and 2.

\section{[Insert Table 1, 2 about here]}

\subsection{Data analysis}

We deployed a multivariate regression approach adopting a Tobit regression. Our dependent variable, namely the Log of Review Helpfulness votes, was regressed against the focal independent variables: power distance (PD), individualism (IDV), masculinity (MAS), uncertainty avoidance (UA), long-term orientation (LTO), and indulgence (IND). We also considered rating, the square of the rating, review length (in characters), and number of helpful votes obtained by a helpful reviewer. We also used control variables such as whether 
the tourist is domestic or not, identity disclosure (borrowed from Gao et al., 2018), a dummy for the gender of the reviewer, the length of stay $(\mathrm{LoS})$, the type of travelling group (solo, couple, etc.), the trip purpose, as well as hotel class and weather the hotel was part of a chain. Our six hypotheses were validated using a Tobit regression that is extremely suitable when variables display normality and when the dependent variable (in our case, the logarithmic transformation of the helpful votes) is censored (Filieri et al., 2019). The model specification is illustrated in Equation 1:

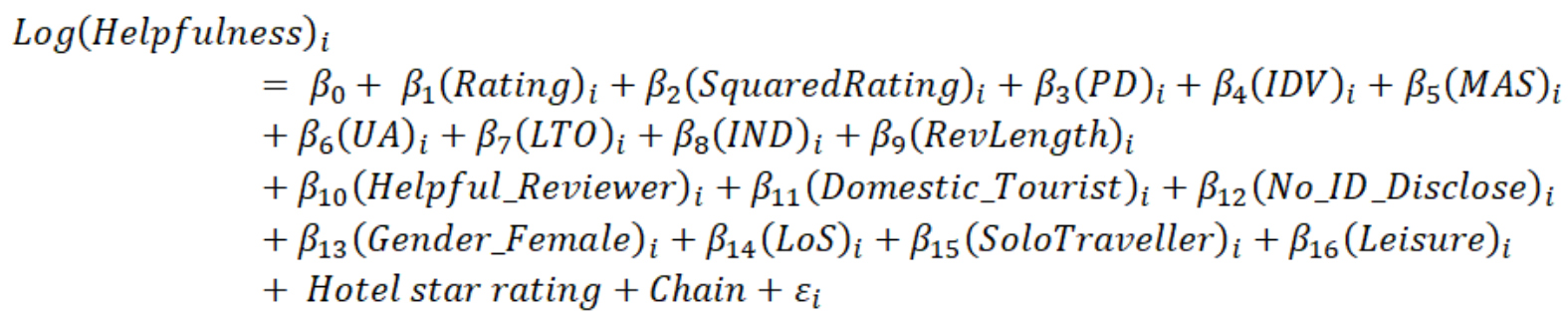

\section{Results}

The results of the analyses are illustrated in Table 3. In more detail, power distance (PD), individualism (IDV), masculinity (MAS), uncertainty avoidance (UA) and indulgence (IND) positively and significantly influence ORH $(\mathrm{p}<0.001)$, while the effect of long-term orientation (LTO), though positive, is non-significant. Therefore, H1, H2, H4, and H6 are supported, while H3 and H5 are rejected.

Among the other variables, review ratings (i.e., review valence) influences negatively ORH $(\mathrm{p}<0.001)$ while its square positively influences our dependent variable. This is consistent with literature suggesting that extreme ratings are perceived as particularly helpful (e.g., Park and Nicolau, 2015; Filieri et al., 2018). Review length has a positive and significant effect on ORH $(\mathrm{p}<0.001)$, which is consistent with previous research showing that longer reviews are more diagnostic (e.g., Mudambi and Schuff, 2010; Kwok and Xie, 2016). The more helpful is considered a reviewer (based on the number of helpful reviews), the higher would be the 
ORH $(\mathrm{p}<0.001)$. Domestic tourists are perceived as helpful reviewers $(\mathrm{p}<0.05)$ probably because they are construed as more knowledgeable about the destination. Reviews from reviewers who do not disclose their personal details (i.e., age and gender) negatively influence ORH as they are probably perceived as less trustworthy consistently with previous findings (e.g., Filieri 2016; Gao et al., 2018). Reviewer's gender seems not to make a statistically significant difference in terms of its effect on ORH. The longer the stay, the higher the probability that the reviewers' review will be voted as helpful. This seems rather reasonable as consumers would perceive reviews from patrons who have experienced the hospitality service for a longer period of time as more knowledgeable due to the time spent in the hotel. Reviews from solo travellers have a negative effect on helpfulness: this might imply that solo travellers' reviews are seen as less objective because they could be more adaptable to different hospitality situations. Last, leisure travellers' reviews are perceived as particularly helpful as, contrarily to business travellers, leisure travellers might be more accurate in their review as they do not travel on business accounts (Schuckert et al., 2015).

\section{[Insert Table 3 about here]}

\section{Discussion}

\subsection{Theoretical contribution}

Our study makes several contributions to marketing literature in the area of eWOM helpfulness. We detail our contributions below.

First, we make a methodological contribution in that we use a big data approach consisting of a large sample of reviews from consumers of different countries (i.e., 81), and posted on an ecommerce platform (Booking.com) and while previous cross-country studies generally compared respondents from two cultures (e.g., West versus East). Existing studies on review helpfulness have focused on surveys (Filieri, 2015) or relatively small dataset of reviews and 
accommodation from TripAdvisor and Yelp (e.g., Park and Nicolau, 2015; Liu and Park, 2015; Kwok and Xie, 2016; Filieri et al., 2018). Big data analysis can improve the accuracy of the predictions relying on extensive consumer data, thus overcoming the limitations of small sample sizes and sampling bias (Yang et al., 2015; Li et al., 2018; Mariani et al., 2018; Mariani and Matarazzo, 2020).

Accordingly, few of them have used data of hotels from third-party travel retailers such as Booking.com, where only verified purchasers can submit a review, thus avoiding the fake reviews bias (Filieri, 2016). We have applied all dimensions of Hofstede's cultural framework to online reviews of hotels and tested our framework using 570,669 consumer reviews of 851 hotels in Rome. By doing so, we contribute to the eWOM literature and to research on the influence of culture on consumer information processing, and specifically on the evaluation of consumer review helpfulness in e-commerce platforms.

Second, previous studies have investigated what makes ORH focusing on the characteristics of the message (e.g., Mudambi and Schuff, 2010) or of the reviewer profile (e.g., Karimi and Wang, 2017) or both (Filieri, 2015). However, no study has considered the role of cultural values in the evaluation of ORH. Thus, this is one of the first studies adopting all the dimensions of Hofstede's cultural framework (2001) in the context of ORH, and particularly to assess whether culture affects the degree of ORH. We find confirmation that the theory is valuable in explaining the operating of cultural effects in the evaluation of $\mathrm{ORH}$ : thus, culture matters in this specific research context.

A third contribution that is related to the previous one concerns more broadly our contribution to the literature investigating the role of cultural differences in consumers' behaviour and specifically in the evaluation of services (e.g., Mattila, 1999, 2000; Liu et al., 2001; Au, Law, Buhalis, 2010) and of eWOM messages. Accordingly, this is one of the first studies that investigated the role of culture in eWOM (Christodoulides et al., 2012; Park and 
Jeon, 2018; Gao et al., 2018; Chiu et al., 2019), and specifically the role of culture in consumers' evaluation of ORH.

\section{Power distance (PD)}

Findings show that reviewers from countries with high PD tend to write more helpful reviews than reviewers from countries with low power distance. This result supports the presence of differences between consumers in high versus low PD cultural contexts observed in offline settings (Liu et al., 2001). This finding may be explained by the fact that reviewers from countries with higher PD tend to be more critical and stricter in their evaluation of hotels and provide lower online hotel ratings than reviewers from low-distance countries (Liu et al., 2001; Gao et al., 2018; Mariani, Di Fatta and Di Felice, 2019). Lower product ratings are generally considered more helpful and attention-catching (Filieri et al., 2019). This result underlines the importance of the dichotomy of low versus high PD in consumer information processing, supporting previous studies' findings that revealed important differences between high and low PD individuals in how they process information in face-to-face WOM (Schumann et al., 2010).

\section{Individualism}

We hypothesized that reviewers from individualistic cultures would write more helpful reviews because, differently than collectivist consumers, they do not conform to previous opinions (Cialdini et al., 1999; Yaveroglu and Donthu, 2002) reviews, and ratings. The findings corroborate this hypothesis, meaning that individualism will predict the degree to which reviews will be voted as helpful.

This result might also be explained by the fact that "collectivists" often show less consideration than do "individualists" for the welfare of strangers (Brewer and Chen, 2007). 
Hence, people from individualist countries may want to help 'stranger' consumers truly, so they write helpful reviews for altruistic motives. This result supports findings from eWOM studies in Western contexts: Hennig Thurau et al. (2003) used a sample of German consumers and found that concern for others was a motive behind electronic word of mouth. Moreover, reviewers from individualistic countries could be more used to articulate their own experience in writing reviews and tend to not conform or be influenced by the opinions of others.

\section{Masculinity}

Contrary to what was hypothesised, findings show that masculinity significantly and positively predicts review helpfulness. We may interpret the result in the following way: masculine societies tend to be less tolerant towards service failure (Crotts and Erdmann, 2000) and therefore will be more likely to voice their disappointment than individuals from feminine societies that instead tend to express a preference for cooperation and a caring attitude for the weak. Therefore, individuals from feminine societies may tend to provide an accommodative answer to a service failure, meaning that they will tend to soften their opinion. This result is particularly interesting as it does not corroborate the non-significant influence in previous studies' findings: for instance, masculinity/femininity was not found to influence service quality expectation formation (Donthu and Yoo, 1998), or the effect of received face-to-face WOM (Schumann et al., 2010).

\section{Uncertainty avoidance (UA)}

Findings show that reviewers from countries with high UA will post reviews that are voted as more helpful than those posted by reviewers from low UA contexts. This result supports our hypothesis and can be explained by the fact that consumers from cultures that tend to avoid 
uncertainty will be more cautious when it comes to making purchase decisions, especially in the context of risky product decisions like services (Murray and Schlacter, 1990). We might expect that reviewers from high UA countries will provide more details in their reviews, and detailed reviews are helpful reviews (Filieri, 2015). Consumers in high UA contexts would provide unambiguous and clear-cut evaluations as they know these will be helpful to other consumers who want to avoid risk like them. Concrete consumer reviews are more diagnostic (Li et al., 2011) and trustworthy (Filieri, 2016) than abstract consumer reviews. Previous research found differences in service quality expectations between consumers high on UA and short-term orientations (Donthu and Yoo, 1998).

\section{Long-term (LTO) and short-term orientation (STO)}

We formulated the hypothesis that reviewers from LTO cultural contexts will write more helpful reviews than reviewers from STO contexts. Our hypothesis was not supported; LTO and STO do not predict ORH. This result can also be explained by the fact that reviewers from cultures with high LTO would probably tend to comment more on how the service provider could improve the service (because they view their relationship with the service provider in the long run) rather than on their actual experience. However, this may not satisfy the information needs of the reader who is interested in the customer's actual experience. This tendency to comment more on what the service provider should do to improve the service may render their reviews more neutral and balanced to allow service providers to rectify or recover from a service failure. As a result, their reviews might be voted as less or not helpful because they are directed to help the service provider and not the other consumers.

\section{Indulgence}


In high-indulgence countries, freedom of speech is seen as important (Hofstede, 2011), and this may lead to think that reviewers from these cultures would be less inhibited in expressing their own ideas and views as they do not feel restrained by societal norms. This means that they will be more inclined to openly express their true opinions, either be extremely good or bad and that their opinions will be perceived as closer to the service experience.

\section{Managerial implications}

The study's findings show that national culture has important effects on the evaluation of ORH of hotels. More specifically, the results of our work show that reviewers from cultural contexts that score high on power distance, individualism, masculinity, uncertainty avoidance, and indulgence are more likely to write helpful reviews. Consequently, hotel managers should pay particular attention to guests coming from countries that score high on these dimensions as their reviews will be particularly helpful to prospects and thus impactful on others' decisions.

Cultural values have an influence on the way consumers process information from online reviews. For example, for consumers from high UA contexts, specific information should be provided in order to avoid ambiguity or clarify potential misunderstandings emerging from consumer reviews. This also implies that the response of the hotel manager to some consumer reviews (e.g., negative ones) could be particularly important to reduce the risks emerging from ambiguous situations or evaluations caused, for example, by inconsistent judgments in consumer reviews.

The results of this study could help hotel managers understand the most effective way to exploit cultural orientations to acquire new customers or to retain existing ones. Hotel managers often incorporate consumer reviews in their corporate websites. An important implication is that they could probably display first the reviews posted by customers from the 
same cultural contexts of the visitors of the website based on the language they choose to browse the website. From our findings, we can infer that consumers might find it particularly helpful to shortlist reviews from hotel guests who share similar cultural values. For instance, it is expected that reviewers from the same cultural context would particularly appreciate reviews written by risk-averse consumers like them.

\section{Limitations and future research}

Our study displays some limitations. First, our results may not be generalizable to different countries or services. Accordingly, to generalize the results of this study, we suggest future research to compare reviews of hotels from different countries as well as services having different levels of complexity and risk.

Another limitation is that we could not control for the origin of the review reader when testing the effect of reviewer's country origin in the relationship between homophily and review helpfulness. Thus, in this context homophily, namely the similarity between the source and the receiver of communication on the basis of similar ascriptive characteristics, such as gender, ethnicity, country of origin, appearance, and the like (McPherson, SmithLovin, and Cook, 2001), may influence consumer's evaluation of review helpfulness. Moreover, future studies could measure consumers' perception of review helpfulness. For instance, services are intangible deeds and performances, and their evaluation may depend on the interaction between a customer and a service provider, which can vary from situation to situation (Zeithaml et al., 1985) (e.g., from country to country).

Furthermore, consumers' evaluation of the helpfulness of a review can be influenced by their previous consumption experiences or by the reputation or the image of the brand (Jiang, Gretzel, and Law, 2014). For example, if a consumer has had previous positive experiences with a hotel brand or the brand is well known worldwide for providing excellent quality 
standards, her/his evaluation of the helpfulness of a highly negative rating may be influenced by this experience or perception of the brand. Thus, future studies could consider adopting surveys or experiments to measure the influence of perceptual factors of review helpfulness such as homophily, perceived brand reputation, and previous experience with a hotel brand. Furthermore, we used the helpful votes as a proxy for helpful reviews following previous research (e.g., Mudambi and Schuff, 2010; Filieri et al., 2018). 


\section{References}

Agyeiwaah, E., Adongo, R., Dimache, A., Wondirad A. (2016). "Make a customer, not a sale: Tourist satisfaction in Hong Kong". Tourism Management, Vol.57, pp.68-79.

Aksoy L., Buoye A., Aksoy P., Larivière B., and Keiningham T.L. (2013). "A Cross-national Investigation of the Satisfaction and Loyalty Linkage for Mobile Telecommunications Services across Eight Countries". Journal of Interactive Marketing, Vol.27 No.1, pp.74-82.

Alhidari, A., Iyer, P., \& Paswan, A. (2015). Personal level antecedents of eWOM and purchase intention, on social networking sites. Journal of Customer Behaviour, Vol. 14 No. 2, pp.107-125.

Ayeh, J.K., Au, N., and Law, R. (2016). "Investigating cross-national heterogeneity in the adoption of online hotel reviews". International Journal of Hospitality Management, Vol.55, pp.142-153.

Barsky, J., and Nash, L. (2002). "Evoking emotion: affective keys to hotel loyalty.” Cornell Hotel and Restaurant Administration Quarterly Vol. 43 No. 1, pp. 39-46.

Brewer, M. B., \& Chen, Y. R. (2007). "Where (who) are collectives in collectivism? Toward conceptual clarification of individualism and collectivism". Psychological review, Vol.114 No.1, pp.133-151.

Butler, E. A., Lee, T. L., \& Gross, J. J. (2007). "Emotion regulation and culture: Are the social consequences of emotion suppression culture-specific? ". Emotion, Vol. 7 No. 1, pp. 30 .

Cialdini, R., Wosinska, W., Barrett, D. W., Butner, J., and Gornik-Durose, M. (1999).

"Compliance with a Request in Two Cultures: The Differential Influence of Social Proof and Commitment/Consistency on Collectivists and Individualists," Personality and Social Psychology Bulletin Vol. 25 No. 10, pp. 1242-1253.

Chen, R.X.Y., Cheung, C., and Law, R. (2012). "A review of the literature on culture in hotel management research: what is the future?" International Journal of Hospitality Management, Vol.31 No.1, pp.52-65.

Chiu, Y. L., Chen, K. H., Wang, J. N., and Hsu, Y. T. (2019). "The impact of online movie word-of-mouth on consumer choice". International Marketing Review, Vol.36 No.6, pp.9961025 .

Christodoulides, G., Michaelidou, N., and Argyriou, E. (2012). "Cross-national differences in e-WOM influence". European Journal of Marketing, Vol. 46 No. 11/12, pp. 1689-1707

Crotts, J.C., Erdmann, R. (2000). "Does national culture influence consumers' evaluation of travel services? A test of Hofstede's model of cross-cultural differences". Managing Service Quality: An International Journal, Vol. 10 No. 6, pp. 410-419.

Liu, B.S.C., Furrer, O. and Sudharshan, D. (2001). "The relationships between culture and behavioral intentions toward services". Journal of service research, Vol. 4 No. 2, pp.118-129.

De Mooij, M. (2004), Consumer Behavior and Culture: Consequences for Global Marketing and Advertising, Sage Publications, Thousand Oaks, CA.

De Mooij, M. and Hofstede, G. (2002). "Convergence and Divergence in Consumer Behavior: Implications for International Retailing", Journal of Retailing, Vol. 78, pp. 61-69. 
Donthu, N., and Yoo, B. (1998). "Cultural influences on service quality expectations". Journal of service research, Vol. 1 No. 2, pp. 178-186.

Duque, L.C. and Lado, N. (2010). "Cross-cultural comparisons of consumer satisfaction ratings: A perspective from Albert Hirschman's theory". International Marketing Review, Vol.27 No.6, pp.676-693.

Eslami, S. P., \& Ghasemaghaei, M. (2018). "Effects of online review positiveness and review score inconsistency on sales: A comparison by product involvement". Journal of Retailing and Consumer Services, Vol. 45, pp. 74-80.

Fang, B., Ye, Q., Kucukusta, D., and Law, R. (2016). "Analysis of the perceived value of online tourism reviews: influence of readability and reviewer characteristics". Tourism Management Vol.52, pp.498-506.

Fong, J., and Burton, S. (2008). "A cross-cultural comparison of electronic word-of-mouth and country-of-origin effects". Journal of Business Research, Vol.61 No.3, pp.233-242.

Filieri, R. (2015). "What makes online reviews helpful? A diagnosticity-adoption framework to explain informational and normative influences in e-WOM". Journal of Business Research, Vol.68 No.6, pp.1261-1270.

Filieri, R. (2016). "What makes an online consumer review trustworthy? ". Annals of Tourism Research, Vol. 58, pp. 46-64.

Filieri, R., McLeay, F., Tsui, B. and Lin, Z., (2018). "Consumer perceptions of information helpfulness and determinants of purchase intention in online consumer reviews of services". Information \& Management, Vol. 55 No. 8, pp.956-970.

Filieri, R., Raguseo, E., and Vitari, C. (2019). "What moderates the influence of extremely negative ratings? The role of review and reviewer characteristics". International Journal of Hospitality Management, Vol.77, pp.333-341.

Filieri, R., Raguseo, E., and Vitari, C. (2020). "Extremely negative ratings and online consumer review helpfulness: The moderating role of product quality signals". Journal of Travel Research, 0047287520916785.

Filieri, R., Galati, F., and Raguseo, E. (2021). The impact of service attributes and category on eWOM helpfulness: An investigation of extremely negative and positive ratings using latent semantic analytics and regression analysis. Computers in Human Behavior, 114, 106527.

Floyd, K., Freling, R., Alhoqail, S., Cho, H. Y., and Freling, T. (2014). "How online product reviews affect retail sales: A meta-analysis". Journal of Retailing, Vol.90 No.2, pp.217-232.

Fong, L. H. N., Lei, S. S. I., Law, R. (2017). "Asymmetry of hotel ratings on TripAdvisor: Evidence from single-versus dual-valence reviews". Journal of Hospitality Marketing and Management, Vol.26 No.1, pp.67-82.

Frank, B., Abulaiti, G., Herbas Torrico, B., Enkawa, T. (2013). "How do Asia's two most important consumer markets differ? Japanese-Chinese differences in customer satisfaction and its formation". Journal of Business Research, Vol.66 No.12, pp.2397-2405.

Gao, B., Li, X., Liu, S., and Fang, D. (2018). "How power distance affects online hotel ratings: the positive moderating roles of hotel chain and reviewers' travel experience". Tourism Management, Vol.65, pp.176-186. 
Geerts, W. (2018), "Top 100 City Destinations 2018, Euromonitor International." https://go.euromonitor.com/white-paper-travel-2018-100-cities (accessed on 12 November, 2019).

Ghose, A., and Ipeirotis, P. G. (2011). "Estimating the helpfulness and economic impact of product reviews: Mining text and reviewer characteristics". IEEE Transactions on Knowledge and Data Engineering Vol.23 No.10, pp.1498-1512.

Hassan, L. M., Shiu, E., and Walsh, G. (2011). "A multi-country assessment of the long-term orientation scale" International Marketing Review, Vol. 28 No. 1, pp. 81-101.

Herr, P. M., Kardes, F. R., and Kim, J. (1991). "Effects of word-of-mouth and productattribute information on persuasion: An accessibility-diagnosticity perspective". Journal of consumer research, Vol. 17 No. 4, pp. 454-462.

Hofstede, G. (1976). "Nationality and Espoused Values of Managers". Journal of Applied Psychology, Vol.61 No.2, pp.148-155.

Hofstede, G. (1980). Cultures' Consequences: International Differences in Work-related Values. Sage Publications, Newbury Park, CA.

Hofstede, G. (2001). Culture's Consequences: comparing values, behaviors, institutions, and organizations across nations (2nd ed.). Thousand Oaks, CA: SAGE Publications

Hofstede, G. (2011). "Dimensionalizing cultures: The Hofstede model in context". Online readings in psychology and culture, Vol.2 No.1, pp.8.

Hong, H., Xu, D., Wang, A., Fan, W. (2017). "Understanding the determinants of online review helpfulness: A meta-analytical investigation". Decision Support Systems Vol.102, pp.1-11.

Hsieh, A.T., Chang, J. (2005). "The different response to hotels' endorsement advertising by Taiwanese and American tourists". Journal of Travel \& Tourism Marketing, Vol.19 No.4, pp.41-54.

Huang, A. H., Chen, K., Yen, D. C., and Tran, T. P. (2015). "A study of factors that contribute to online review helpfulness". Computers in Human Behavior, Vol.48, pp.17-27.

Karimi, S., and Wang, F. (2017). "Online review helpfulness: Impact of reviewer profile image". Decision Support Systems, Vol.96, pp.39-48.

Khan, M.S., Naumann E., Bateman R., and Haverila M. (2007). "Cross-cultural comparison of customer satisfaction research: USA vs Japan", Qualitative Research in Organizations and Management, Vol.21 No.3, pp.376-396.

Koh, N. S., Hu, N., and Clemons, E. K. (2010). "Do online reviews reflect a product's true perceived quality? An investigation of online movie reviews across cultures". Electronic Commerce Research and Applications, Vol.9 No.5, pp.374-385.

Kim, J.-H. and Kim C. (2010). "E-service quality perceptions: A cross-cultural comparison of American and Korean consumers". Journal of Research in Interactive Marketing, Vol.4 No.3, pp.257-275.

Korfiatis, N., García-Bariocanal, E., and Sánchez-Alonso, S. (2012). "Evaluating content quality and helpfulness of online product reviews: The interplay of review helpfulness vs. review content". Electronic Commerce Research and Applications Vol.11 No.3, pp. 205-217. 
Kwok, L., and Xie, K. L. (2016). "Factors contributing to the helpfulness of online hotel reviews". International Journal of Contemporary Hospitality Management, Vol. 28 No. 10, pp. 2156-2177.

Jiang, Z.H. and Benbasat, I. (2007). "Investigating the influence of the functional mechanisms of online product presentations". Information Systems Research Vol.18 No.4, pp.221-244.

Jin, B., Park, J., Kim, J. (2008). "Cross cultural examination of the relationships among firm reputation, e-satisfaction, e-trust, and e-loyalty". International Marketing Review, Vol.25 No.3, pp.324-337.

Ladhari, R., Pons, F., Bressolles, G., and Zins, M. (2011). "Culture and personal values: How they influence perceived service quality". Journal of Business Research, Vol. 64 No. 9, pp. 951-957.

Lam, D., Lee, A., and Mizerski, R. (2009). "The effects of cultural values in word-of-mouth communication". Journal of international marketing, Vol.17 No.3, pp.55-70.

Laroche, M., Kalamas, M., and Cleveland, M. (2005). "I" versus "we" how individualists and collectivists use information sources to formulate their service expectations". International marketing review, Vol.22 No.3, pp.279-308.

Li, J., Xu, L., Tang, L., Wang, S., \& Li, L. (2018). "Big data in tourism research: A literature review". Tourism Management, Vol. 68, pp. 301-323.

Liu, Z., and Park, S. (2015). "What makes a useful online review? Implication for travel product websites". Tourism Management, Vol.47, pp.140-151.

Liu, B. S.-C., O. Furrer, and D. Sudharshan (2001). "The Relationships Between Culture and Behavioral Intentions Toward Services". Journal of Service Research, Vol.4 No.2, pp.11830

Liu R. R., and McClure P. (2001). "Recognizing cross-cultural differences in consumer complaint behavior and intentions: An empirical examination". Journal of Consumer Marketing, Vol.18 No.1, pp.54-74.

Long, J. S. (1997). Regression Models for Categorical and Limited Dependent Variables, Thousand Oaks, CA: Sage Publications.

Manzur, L., and Jogaratnam, G. (2006). "Impression management and the hospitality service encounter: Cross-cultural differences". Journal of Travel and Tourism Marketing, Vol.20 No. 3-4, pp.21-32

Mariani, M., Baggio, R., Fuchs, M., \& Höepken, W. (2018). Business intelligence and big data in hospitality and tourism: a systematic literature review. International Journal of Contemporary Hospitality Management, Vol. 30 No. 12, pp. 3514-3554.

Mariani, M.M., Di Fatta, G., Di Felice, M. (2018). "Understanding Customer Satisfaction with Services by leveraging Big Data: the Role of Services Attributes and Consumers' Cultural Background", IEEE Access, 7, 8580523, pp. 8195-8208.

Mariani, M.M. and Borghi, M. (2018). "Effects of the booking.com rating system: bringing hotel class into the picture". Tourism Management, Vol.66, pp.47-52.

Mariani, M. M., Borghi, M., and Okumus, F. (2020). "Unravelling the effects of cultural differences in the online appraisal of hospitality and tourism services". International Journal of Hospitality Management, Vol. 90, pp. 102606. 
Mariani, M. M., \& Borghi, M. (2020). Online review helpfulness and firms' financial performance: an empirical study in a service industry. International Journal of Electronic Commerce, 24(4), 421-449.

Mariani, M. M., \& Matarazzo, M. (2020). Does cultural distance affect online review ratings? Measuring international customers' satisfaction with services leveraging digital platforms and big data. Journal of Management and Governance, 1-22, https://doi.org/10.1007/s10997-02009531-z

Mattila, A.S. (2000). "The impact of culture and gender on customer evaluations of service encounters". Journal of Hospitality and Tourism Research, Vol.24 No.2, pp.263-273.

Mattila, A.S. (1999). "The role of culture in the service evaluation process". Journal of Service Research, Vol.1 No.3, pp.250-261.

Mattila, A.S., and Choi, S. (2006). "A cross-cultural comparison of perceived fairness and satisfaction in the context of hotel room pricing". International Journal of Hospitality Management, Vol.25 No.1, pp.146-153.

Michaelidou, N., Christodoulides, G., Cadogan, J. W., and Veloutsou, C. (2015). "Consumerbased brand equity measurement: lessons learned from an international study". International Marketing Review, Vol.32 No.3/4, pp.307-328.

Money, R. B., \& Crotts, J. C. (2003). The effect of uncertainty avoidance on information search, planning, and purchases of international travel vacations. Tourism Management, 24(2), 191-202.

Morgeson III, F. V., Sharma, P. N., and Hult, G. T. M. (2015). "Cross-national differences in consumer satisfaction: mobile services in emerging and developed markets". Journal of International Marketing, Vol.23 No.2, pp.1-24.

Mintel (2015). American Lifestyles 2015: The Connected Consumer e Seeking Validation from the Online Collective - US - April 2015. Available at:

https://reports.mintel.com/display/716531/

McPherson, M., Smith-Lovin, L., and Cook, J. M. (2001). "Birds of a feather: Homophily in social networks". Annual Review of Sociology Vol.27, pp.415-444.

Mudambi, S. M. and Schuff, D. (2010). "What Makes a Helpful Online Review? A Study of Customer Reviews on Amazon.com". MIS Quarterly Vol.34, No.1, pp.185-200.

Murray, K. B., and Schlacter, J. L. (1990). "The impact of services versus goods on consumers' assessment of perceived risk and variability". Journal of the Academy of Marketing science, Vol.18 No.1, pp.51-65.

Pan, Y., and Zhang, J. Q. (2011). "Born unequal: A study of the helpfulness of user-generated product reviews". Journal of Retailing, Vol.87 No.4, pp.598-612.

Park, H. H., and Jeon, J. O. (2018). "The impact of mixed eWOM sequence on brand attitude change: Cross-cultural differences". International Marketing Review, Vol.35 No.3, pp.390411. 
Park, D.-H., Lee, J., and Han, I. (2007). "The effect of online consumer reviews on consumer purchasing intention: The moderating role of involvement". International Journal of Electronic Commerce, Vol.11 No.4, pp.125-148.

Park, D.-H., and Lee, J. (2008). "E-WOM overload and its effect on consumer behavioural intention depending on consumer involvement". Electronic Commerce Research and Applications, Vol.7 No.4, pp.386-398.

Park, S., and Nicolau, J. L. (2015). "Asymmetric effects of online consumer reviews". Annals of Tourism Research, Vol.50, pp.67-83.

Petty, R. E., Cacioppo, J. T., and Schumann, D. (1983). "Central and peripheral routes to advertising effectiveness: The moderating role of involvement". Journal of consumer research, Vol. 10 No 2, pp. 135-146.

Racherla, P., and Friske, W. (2012). "Perceived 'Usefulness' of Online Consumer Reviews: An Exploratory Investigation across Three Services Categories". Electronic Commerce Research and Applications, Vol.11 No.6, pp.548-59.

Raguseo, E. and Vitari, C. (2016). "The Effect of Brand on the Impact of e-WOM on Hotels' Financial Performance". International Journal of Electronic Commerce, Vol.21 No.2, pp.121.

Sharma, P., Wu, Z., and Su, Y (2016). "Role of personal cultural orientations in intercultural service encounters". Journal of Services Marketing, Vol.30, No.2, pp.223-237.

Schumann, J. H., Wangenheim, F. V., Stringfellow, A., Yang, Z., Blazevic, V., Praxmarer, S., ... and Jiménez, F. R. (2010). "Cross-cultural differences in the effect of received word-ofmouth referral in relational service exchange". Journal of International Marketing, Vol.18 No.3, pp.62-80.

Soares, A.M., Farhangmehr, M., Shoham, A. (2007). "Hofstede's dimensions of culture in international marketing studies”. Journal of Business Research, Vol.60, pp.277-284.

Stamolampros, P., Korfiatis, N., Kourouthanassis, P., and Symitsi, E. (2019). "Flying to quality: Cultural influences on online reviews". Journal of Travel Research, Vol.58 No.3, pp.496-511.

Sun, X., Han, M., \& Feng, J. (2019). "Helpfulness of online reviews: Examining review informativeness and classification thresholds by search products and experience products". Decision Support Systems, Vol.124 (September 2019), pp. 113099.

Tam, J.L.M., Sharma, P., and Kim, N. (2016). "Attribution of success and failure in intercultural service encounters: the moderating role of personal cultural orientations". Journal of Services Marketing, Vol.30 No.6, pp.643-658.

Voss, C.A., Roth A.V., Rosenzweig E.D., Blackmon K., and Chase R.B. (2004). "A tale of two countries' conservatism, Service quality, and feedback on customer satisfaction". Journal of Service Research, Vol.6 No.3, pp.212-230.

Wong, J., Law, R. (2003). "Difference in shopping satisfaction levels: A study of tourists in Hong Kong”. Tourism Management, Vol.24 No.4, pp.401-410.

Yang, X., Pan, B., Evans, J. A., \& Lv, B. (2015). "Forecasting Chinese tourist volume with search engine data. Tourism Management, Vol. 46, pp. 386-397.

Yaveroglu, I. S., and Donthu, N. (2002). "Cultural influences on the diffusion of new products”. Journal of International Consumer Marketing, Vol. 14 No. 4, pp. 49-63. 
Yin, D., Bond, S., and Zhang, H. (2014). "Anxious or angry? Effects of discrete emotions on the perceived helpfulness of online reviews". MIS Quarterly, Vol.38 No 2, pp.539-560. 